\title{
Control of Competences Formation of Foreign Language Bachelor Students on the Basis of LMS Moodle
}

\author{
Tatjana I. Zaburdaeva ${ }^{1}$, Maria A. Serebryakova ${ }^{1}$, Inna V. Kazantseva ${ }^{1}$, Anna L. Kolyago ${ }^{1} \&$ Olga V. Ivanova ${ }^{1}$ \\ ${ }^{1}$ Mari State University, Yoshkar-Ola, Russia \\ Correspondence: Tatjana I. Zaburdaeva, Foreign Languages Faculty, Mari State University, 1 Lenin Square, \\ 424000, Yoshkar-Ola, Russia. Tel: 7-836-242-0830. E-mail: tanja-zab@yandex.ru
}

$\begin{array}{lc}\text { Received: February 21, } 2015 & \text { Accepted: March 15, } 2015 \quad \text { Online Published: April 29, } 2015 \\ \text { doi:10.5539/res.v7n8p295 } & \text { URL: http://dx.doi.org/10.5539/res.v7n8p295 }\end{array}$

\begin{abstract}
In connection with the transition to a two-tier system of training and educational programs development according to the new Federal State Educational Sandards it is necessary to improve measurement and control tools. The article gives special attention to the development of specific diagnostic tests for monitoring competences formation. The main objective of such tests is that the student, performing suggested tasks, is involved into active thinking and is to make informed decisions when problems occur. Their main aim is not to measure the relevant knowledge but to assess his level of understanding and professional thinking. The research work is relevant due to contradiction between the necessity to control the level of different competences formation and insufficient development of techniques for their assessment. The article presents an algorithm for development of tests in foreign languages, taking into account the provisions of the Common European competences. The paper is concerned with the possibilities the learning management system Moodle in the control of competencies formation of bachelor students of the Faculty of Foreign Languages by means of modern facilities. Built-in test system in Moodle provides a great opportunity for creating on-line tests with the following approaches: direct addition of the test in the course, followed by the supplement of test items, and creating new test based on a bank of questions.
\end{abstract}

Keywords: distractor, validity, relevancy, specification, competences formation, learning management system, Moodle

\section{Introduction}

Nowadays the ideas of competence-based approach has been developing in the system of education, the essence of which is discussed in the works of V. I. Baidenko, E. F. Zeer, I. A. Zimnaya, R. P. Milrud, Y. G. Tatur, A. V. Khutorskoy, J. Raven, W. Hutmacher and others.

Zimnyaya (2006) in her research of the problems of competence-based approach in the education denotes that competence-based education was forming in the 70s in the USA according to the way N. Chomsky (1965, Massachusetts University) employs the term "competence" as applied to linguistics and grammar (Isaeva, 2003).

At the same period in the work of R. White Motivation reconsidered: the Concept of competence (1959) the content of the category of competence is filled with person-oriented components, motivation included (White, 1959).

Survey of the works on the problem of competences (N. Chomsky, R. White, G. Raven, N. V. Kuzmina, A. K. Markova, V. N. Kunitsina, G. E. Belitskaya et al.) allows us to select three periods in the development of the competence-based approach in education.

The first one (1960-1970s) is characterized by introduction of the notion "competence" in the scientific apparatus, creation of the background of the differences in the notions competence and competency.

The second period (1970-1990s) is characterized by the use of the category "competence" in the theory and practice of teaching languages, especially foreign languages, and also in management, business and teaching communication, the content of the notion "social competences" was developed.

The third period of the development of the competence-based approach is characterized in the papers of UNESCO with the definition of key competences that should be considered as the result of education.

In the symposium which was held in Bern (1996) on the program of the Council of Europe the educators discussed 
problems of the importance of reforming the system of education and the definition of key competences that students should acquire to get ready for higher education and employment (Hutmacher, 1997).

In the summary of the symposium written by Walo Hutmacher it was pointed out that the notion "competence" is not clearly defined though it is used in some other notions such as skill, competency, ability, mastery, craftsmanship. Though, in his opinion, there is an agreement that the notion of competency lies fairly firmly within the field of "knowing how" rather than "knowing that" (Hutmacher, 1997).

It is evident that key competences can be described as a general and wide definition of a proper demonstration of a person's social life in a modern society.

W. Hutmacher gives the definition of five key competences which were chosen by the Council of Europe for all young Europeans. These are: political and social competencies, competencies relating to life in a multicultural society, competencies relating to the mastery of oral and written communication, competencies associated with the emergence of the information society, the capacity to learn throughout life as the basis of lifelong learning in both occupational contexts and individual and social life (Hutmacher, 1997).

Researchers prove the fact in Russia the notion "competence" was defined in "The concept of modernization of Russian education for the period up to 2010 " as "an integrated system of universal knowledge, skills and experience of independent activity and personal responsibility" (Ivanova, 2012).

Russia joined the Bologna Process in 2003 and it meant the reforming of all the system of higher education. One of the dramatic changes is the shift of emphasis from the content to the results of education, which are defined in FSES HPE as common cultural and professional competences.

In the conditions of the transition to the two-tier higher education system and development of curricula in accordance with new Federal State Education Standards (FSES) it is necessary to improve test and evaluation materials.

The assessment of the quality of professional training of bachelors of linguistic specialties and the informatization of the process of assessment of competences are of great current importance.

First of all, it is supposed to have a definite set of methodic instruments enabling to assess objectively the procedure of diagnostics of the level of main professional competences of students getting the bachelor's degree in "Foreign Languages" in the area of "Teacher Training Education". It is the set of forming competences that further determines the status of a bachelor not only as a person owning professional competences but also as an active subject of professional activity.

Our research work is relevant due to contradiction between the necessity to control the level of formation of different competences and insufficient development of techniques for their assessment.

Nowadays in the practice of using testing techniques in the system of higher education there are contradictions between:

- The demand for reliable and current information about the quality of educational results of the students and the impossibility to get it because of the lack standardized funds of assessment techniques;

- The necessity to improve the quality of tests and methods of assessment which are used but don't give the objective assessment of their quality;

- The purpose of the assessment and impossibility of their full realization because of the absence of integrated approach to the use of relevant methods of assessment of the quality of tests;

- The demand for the technology of complex assessment of the quality of tests using which will enable to control with the help of reliable and valid tests and the absence of such a technology.

\section{Results and Discussions}

Professional competence of future teachers consists of common cultural, professional and subject competence. Common cultural and professional competences are described in FSES in the area of "050100.62 Teacher Training Education", and subject competence, prescribed according to the professional training of future teachers. Therefore, training of the future teachers should be directed to the formation of these competences (Kolyago \& Nikitin, 2014).

Each student getting the bachelor's degree in "Foreign Languages" in the area of "050100.62 Teacher Training Education" must have at least a basic level of formation of the following competences:

CC-6-Knows the rules of vocabulary and pronunciation, grammar, spelling and punctuation. Is able to state his 
ideas. Has the skills of verbal and non-verbal communication.

CC-10 - Knows basic dictionary necessary for conversational command of a foreign language, basic grammar rules of a foreign language in the area of oral speech. Is able to construct appropriate and coherent oral speech in a foreign language, to use different forms and kinds of oral communication in a foreign language in the study. Has the skills of comprehension of oral speech in a foreign language, pronunciation skills in a foreign language, basic communicative grammar structures which are most commonly used in oral speech.

CC-16 - Knows the rules of vocabulary and pronunciation, grammar; requirements for constructing of coherent and clear speech. Has the skills to construct oral speech logically.

PC-1-Knows the basic educational programs of basic and elective courses; is able to deal with the modern pedagogical technologies, taking into account peculiarities of the educational process, to define the aims and objectives of the cooperative activity.

PC-9-Is able to analyze the logic of the development of ideas in oral and written statements; has the skills of verbal and non-verbal communication; Is able to state his ideas with argumentation.

In accordance with FSES of Bachelor's Degree in this area of study the assessment of the quality of students' development in main educational programs includes current monitoring of academic progress, interim and final state attestation of students.

For attestation of the students for their personal achievements' correspondence to phased demands of an educational program (current monitoring and interim attestation) funds of assessment techniques are worked out and they consist of typical tasks, control works, tests which are used for assessing knowledge, skills and a level of acquired competences.

Our research is focused on a bank of special tests for diagnosing professional competences. The tests are aimed to make a student think over, search for and take a reasonable decision while solving a problem or being involved in suggested activities. In other words, the tests are not the means of measuring means of knowledge, but they are to assess the student's level of understanding and professional thinking.

In the process of designing tests it is necessary to pay attention to the fact that in practice professional activity is a definite complex of typical problems to be solved by the student. Consequently, professional competences may be defined as student's readiness or ability to analyze independently or find a practical solution of significant professional problems, typical problems (problematic situations) on the basis of acquired knowledge, formed skills and accumulated experience.

Tests realized on the basis of different e-learning systems may be regarded as one of the variants of these tasks (problematic situations)

Evaluation criteria and interpretation of results depends on the kind of abilities which are being assessed: receptive (reading, listening comprehension) or productive (speaking or writing). The thing to discuss is objectiveness of assessment which is influenced by the following factors:

1) Materials and format of the test.

2) Ways of assessment.

a) Standard ways of assessment (assessment of the accuracy of speech, analytical assessment, the integrity of the assessment.

b) Clear criteria of the assessment.

c) Competency of test experts, participating in assessment.

d) Feedback between a test expert and an examine.

Having analyzed different approaches to the problem of design of tests for control of formation of language and speech skills in a foreign language, 4 main phases may be distinguished:

1) Definition of the level of formation of competences.

2) Selection of authentic materials.

3) Clear formulation of the task in accordance with what we want to see as a result.

4) Designing the specifications of the task on the basis of which a relevance of any test is checked (the purpose of the test, for what age group it is designed, value of each item, how many points a person under test may get, etc.) (Hennig, 1982). 
Each test which is worked out is supposed to have a specification - a document which serves a base for designing test items with given quality indicators. Specification of a test is designed for further determination of the test's validity and relevancy (Weir, 2005). The example below shows a specification of a multiple-choice test for checking reading comprehension.

Table 1. An example of specification for checking reading comprehension

\begin{tabular}{ll}
$\begin{array}{l}\text { Comprehensible by learner } \\
\text { at CEF level }\end{array}$ & \\
\hline Age-group sector & teenagers and adults \\
Domain & Public domain \\
Overall reading & Can understand short, simple texts containing the highest frequency \\
comprehension & vocabulary. \\
Reading for information & Can identify specific information in simple written materials, such as \\
and argument & letters, brochures and short newspaper articles describing events. \\
Text source & Genuine, magazine \\
Authenticity & adapted/ simplified \\
Discourse type & Narrative \\
Topic & Free time and entertainment \\
Nature of content & Mostly concrete \\
Text length & 200 words \\
Vocabulary & only frequently occurring \\
Grammar & simple structures only \\
Source of information & Magazine "People" \\
\hline
\end{tabular}

Algorithm of designing tests for checking the formation of reading skills implies recording of the following criteria:

A. Choice of the purpose (global/selective or detailed understanding).

B. Specification in accordance with level (A1-C2) of European competences what the students must be able to do and choose a suitable type of the text (Glaboniat \& Müller, 2003).

C. Selecting an authentic text in the Internet taking into account the suitable size and duration in accordance with English and German exams-KET; PET; FCE; CAE; PCE;Gl, TELC, ÖSD on the levels A1-C1, within the limits of ALTE (Association of Language Testers in Europe).

Table 2. Test duration (reading)

\begin{tabular}{llllll}
\hline & \multicolumn{5}{c}{ Time and size } \\
\cline { 2 - 6 } $\begin{array}{l}\text { Common } \\
\text { European level }\end{array}$ & A 1 & B 1 & B 2 & C 1 \\
\hline Reading & 25 min. & 30 min. & 70 min. & 80 min. & 70 min. \\
& $\approx 400$ words & $\approx 500$ words & $\approx 1,000$ words & $\approx 1,400$ words & $\approx 1,500$ words. \\
\hline
\end{tabular}

D. Clear formulation of the instruction and design of test items

Common rules for designing testing items on reading are:

- Multiple-choice items may consist of 3 and 4 options:

- A1-B1-3 options; B2-C2-4 options; 
- If a subtest for detailed understanding has 1 item for global understanding it must be situated at the end of the test (for instance, after four items for checking global understanding). It may be designed both for one paragraph or the whole text.

- Items must correspond to the order of paragraphs in the text.

— Item of the type "True/False" for reading comprehension is acceptable only at levels A1-A2.

- If a subtest consists of 10 items only 3 items may be designed for checking global understanding.

— Items on matching are suitable for checking selective and global understanding, but not detailed.

- With the reduction of the text to the necessary size a whole paragraph must be crossed out but not a sentence within the paragraph (in the latter case it is very difficult to write distractors).

- The example of how to do the task must be after the direction before the task and not before the text.

- It is not advisable to have pictures in the texts as they often misinform the readers (Hennig, 1982).

For checking the formation of writing skills it is necessary to take the following parameters into consideration:

Table 3. Test duration (writing)

\begin{tabular}{|c|c|c|c|c|c|}
\hline \multirow[b]{2}{*}{ Common } & \multirow[b]{2}{*}{ A 1} & \multicolumn{3}{|c|}{ Time and size } & \multirow[b]{2}{*}{ C 1} \\
\hline & & A 2 & B 1 & B 2 & \\
\hline \multicolumn{6}{|c|}{ European level } \\
\hline \multirow[t]{2}{*}{ Writing } & $20 \mathrm{~min}$. & $30 \mathrm{~min}$. & $30 \mathrm{~min}$. & $65 \mathrm{~min}$. & $65 \mathrm{~min}$. \\
\hline & 30 words & 50 words & 100 words & 150 words & 200 words \\
\hline
\end{tabular}

While assessing the results of written tasks of level B1-C1 we take into consideration assessment criteria represented in Appendix A.

While assessing the results of tests the main task is to find out how high and low level examinees did the test. Qualitative analysis of the components of the test, like multiple choice, shows Facility Value and reliability of distractors, that is calculated on the basis of percentage fulfillment of the whole test and the choice of distractor by high and low level examinees.

Table 4. Example of analysis of test item fulfillment (multiple choice)

\begin{tabular}{|c|c|c|c|c|c|c|c|c|}
\hline \multirow[t]{2}{*}{ Item name } & \multirow{2}{*}{$\begin{array}{l}\text { Proportion } \\
\text { right }\end{array}$} & \multirow{2}{*}{$\begin{array}{l}\text { Discrimination } \\
\text { index }\end{array}$} & \multirow{2}{*}{$\begin{array}{l}\text { Point } \\
\text { biserial } \\
\text { correlation }\end{array}$} & \multirow[t]{2}{*}{ Total } & \multicolumn{2}{|c|}{ \% Endorsing } & \multirow{2}{*}{$\begin{array}{l}\text { Point } \\
\text { biserial } \\
\text { correlation }\end{array}$} & \multirow[t]{2}{*}{ Key } \\
\hline & & & & & Low & High & & \\
\hline \multirow[t]{6}{*}{ Subtest 1:1 } & 0.72 & 0.37 & 0.30 & $\mathrm{a}$ & 5 & 92 & 0.30 & $*$ \\
\hline & & & & 72 & & & & \\
\hline & & & & $\mathrm{b}$ & 38 & 8 & -0.25 & \\
\hline & & & & 24 & & & & \\
\hline & & & & $\mathrm{c}$ & 7 & 0 & -0.15 & \\
\hline & & & & 4 & & & & \\
\hline \multirow[t]{6}{*}{ Subtest 1:2 } & 0.86 & 0.26 & 0.32 & $\mathrm{a}$ & 12 & 0 & -0.23 & \\
\hline & & & & 4 & & & & \\
\hline & & & & $\mathrm{b}$ & 15 & 0 & -0.22 & \\
\hline & & & & 10 & & & & \\
\hline & & & & $\mathrm{c}$ & 74 & 100 & 0.32 & $*$ \\
\hline & & & & 86 & & & & \\
\hline
\end{tabular}


The first column (Item name) shows the number of the item.

This analysis reveals:

1) Proportion right.

Proportion right is expressed by the number of correct answers in one item. The index can be between 1.00 and 0.00 . The index can be between 1.00 (the item is very easy, all candidates did this item) and 0.00 (the item is very difficult, nobody did it). The higher this index, the easier the task is. An acceptable index is between 0.30 and 0.80 .

\section{2) Discrimination of items}

This index shows how one item was done by low-level examinees and how many high-level examinees did it.

This item must be done more successfully by high-level examinees.

There are two methods in German testology, which are used to assess discrimination. They are:

— Discrimination index;

- Point biserial correlation.

Discrimination index can be between -1 and +1 . Discrimination index +1 means that all high-level examinees did the item correctly and all low-level examinees did this item wrong. Discrimination index -1 means, that all high-level examinees did the item wrong and all low-level examinees did the item correctly. In this case the item isn't acceptable. Items with Discrimination index 0.25 and higher are acceptable.

Point biserial correlation 0.30 and higher is acceptable. Negative result means that high-level examinees did the item wrong. The reason for this may be the fact that next to the correct answer is also correct distractor.

1) Description of distractors.

In classical statistical analysis in the right part of table options for each items are analyzed by test experts of Cambridge University (and in German, too) separately.

The column Total shows, how often given answers are chosen in one item. The column endorsing Low shows, how often given options are chosen by all low-level examinees. The column endorsing High shows how often possible option was chosen by high-level examinees. Besides this, in the column Point biserial correlation we see the percentage correlation for every option. Correlation between distractors must be negative, because distractors of one item mustn't be chosen as correct answers by high-level examinees. The column Key shows the correct answer. This answer is marked by the symbol (Zaburdaeva, 2013, 2014).

According to the common European Framework of reference, the criteria mentioned above, as well as the peculiarities of the specifications and characteristics of subtest and distractors are taken into account while introducing test tasks into educational process. They are considered modern forms of competences formation control according to the demands of the Federal State Educational Standard. Towards this end, we successfully apply e-learning possibilities, Moodle in particular. The word Moodle is an abbreviation for Modular Object-Oriented Dynamic Learning Environment, it represents Learning Management System (LMS), based on computer and Internet technologies, for guiding educational process.

Educational possibilities of this platform are quite enormous, its pedagogical tools allow not just to pass knowledge but also to monitor the results of education with the help of tests and specially prepared tasks. Having created his personal course the teacher organizes students' independent work offering information with the help of files, archives, web pages and web-lections. Built-in Web 2.0 components facilitate in organizing joint educational and research work with the help of file storage, portfolios, workshops, chats, forums. Besides, Moodle system allows to work out and to put forward complex research tasks, which require further demonstration of students' knowledge and skills in the audit area.

Teachers can realize the control of students' competences formation via special rating system by collecting and analyzing the information about completed work. We obtain data from graphs, charts and diagrams constructed by the system itself.

With a didactic point of view LMS Moodle is a free learning management system, which aims to organize cooperation between teachers and students. It can be effectively used both in the remote and full-time study. The program allows to create interactive communication environment and an effective system of knowledge control (tasks, polls, quizzes, lectures, seminars); to organize differentiated group work; to monitor all students' activities; to inform them about coming events. 
Thus, the software Moodle is:

- Interoperable, providing an opportunity for using different computer technologies;

- Durable, allowing reuse and interchange of the course components;

- Adaptive, making possible to include new information technologies without having to reconfigure the entire system;

- Complex, allowing to organize the learning process and at the same time to carry out constant control over it;

- Open, giving an opportunity to work with the system both locally in the classroom, as well as remotely from home.

As a progressive and constantly evolving system, Moodle offers the flexibility of the learning process as well as availability and variation of all necessary controls. Courses are design in the form of modules that allows to organize both final and intermediate control throughout the course. Built-in test system in Moodle provides a great opportunity for creating on-line tests. We use two approaches in this area: direct addition to the course of the test itself, followed by the addition of test items, and the creation of new tests based on the bank's issues. The second approach demands more time, but at the same time offers teachers additional opportunities. In this case, all questions are constructed in the course categories and subcategories, which facilitates searching the database.

Speaking about tests cases on the basis of this educational platform, we should mention the technical possibility of creating different types of test items. This can be achieved by multiple choice, when a student chooses an answer to the question from several options offered to him, wherein there can be several correct answers. The assessment of this type of job determines how much in percentage terms of the total number of test points a student will receive for the correct answer. In addition, we can reduce his overall percentage of the test results by setting penalties when choosing an incorrect response. Thus, correct options are assigned with positive points, but wrong ones with negative. The undoubted advantage of the system is the ability to create a comment to every answer that allows the student to understand his mistake. This technical capability is especially applicable for intermediate control.

Test type "Short answer" involves self-administration of the right variant. To ensure the reliability of this task, you must provide all possible options for the correct formulation of a response while preparing the test. Here the percentage of the assessment can be varied in cases where the test gives a partially correct answer.

When a student is offered to perform the task called "Matching", he is supposed to compare elements of two lists. To improve the reliability of the assignment the teacher can increase the number of the second list elements. A variant of this task can also be a random question, answers to which may be the elements of other issues, randomly selected by the system by mixing several questions.

Question type "Embedded answers" can contain a combination of options in the form of a multiple choice or it can suggest a student to enter short answer on his own.

"Essay" is an open-ended task, requiring detailed answers - reviews, essays, reports. This question is evaluated by the teacher and allows him to assess not only lexical and grammatical skills, but also the skills of spelling and composition.

A "True/False" task offers to choose the correct answer from the two proposed, here we also recommend to introduce penalties for choosing the wrong answer. This type of question is the most rarely used one in the system, as there is a high probability of guessing the correct answer.

The system allows the teacher to monitor not only the participation of the users, but also the results of the subject learning. It helps to monitor the formation of competencies embedded in a matrix of the basic educational program.

Figure 1 shows general information about the test including averages of the final testing: average rating of the first and subsequent attempts, the estimated number of attempts, the median estimates, standard deviation, skewness distribution, the ratio of errors, standard error. This statistic gives a qualitative description of the proposed test and indicates if there is any need for an adjustment to its content. 


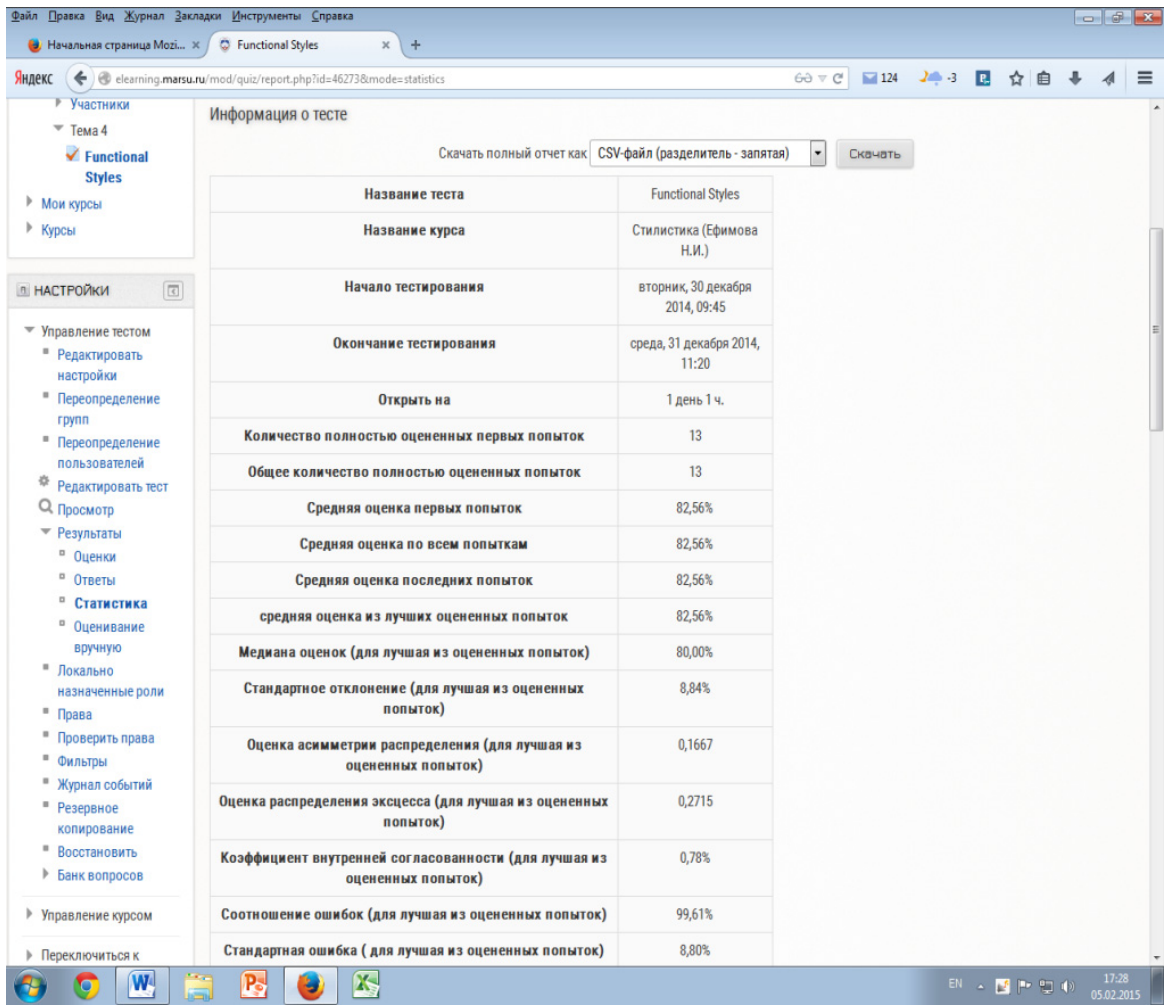

Figure 1. Information about the test

This program allows you not only to calculate the test results, but also to conduct its analysis (Figure 2). You can use it to determine the safety factor, the standard error of measurement and other information on the test results of the test and its features. The statistics include difficult index, random guess score, effective weight, discriminative efficiency and discrimination index for each task.

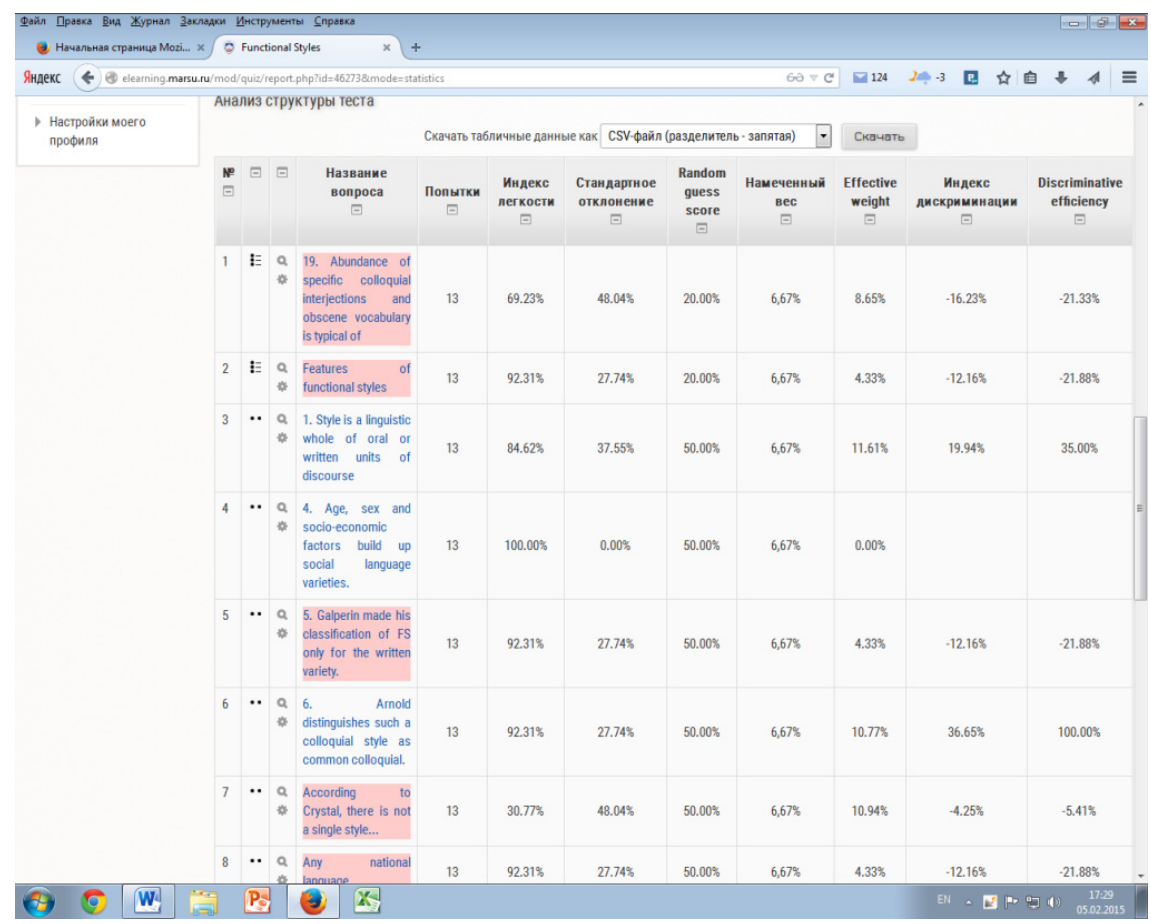

Figure 2. Test structure analysis 1 
However, the interpretation of the results must be approached with caution. Test researchers (Linn, 2001) attract our attention to the following factors:

1) Discrimination factor does not indicate test validity. However, the best measure of the specific achievements, we are interested in the evaluation, is usually a general result of the achievement test, which we have designed themselves, as each classroom test correlates with specific learning objectives and course content. Even standardized tests that are identical in terms of content are not usually suitable as an independent criterion, since they are more focused on the general objectives and not on purpose, measured by classroom test on a particular subject. The use of a common test result as a basis to select advanced and poor students is fully justified as long as we remember that we are using the internal criterion. Therefore, our analysis tasks proves the internal consistency of the test, rather than its validity; that is, we define how each test task reflects the entire test contents. Data obtained from the analysis of the test results can be interpreted as evidence of the test task validity only if validity of the whole test is proved or completely grounded.

2) A low Discrimination Index doesn't always indicate ineffectiveness of the test item. Tasks that are poor in revealing students' strengths and weaknesses should be checked for the presence of ambiguity, tips and other technical shortcomings. If there are not any of them detected and assignments provide important educational conclusions, they should be used in the future. Any task that has positive discrimination contributes to the measurement of student's achievement; discrimination factor may be low not because of technical shortcomings, but for another reason. Since the majority of classroom tests measure different types of educational findings, low positive discrimination factor is the rule rather than the exception. The results of tasks analysis are important when discussing the test with students, in planning additional independent work, and also in designing, selecting and adjusting the test tasks for improving the educational process.

Many aspects of integrated achievements can be measured by objective and subjective means. Complete achievements include a variety of learning outcomes, for example: an ability to apply maxims, to interpret relationships, to draw conclusions, to recognize the relevance of the information to hypothesize, to make valid conclusions, to see the problem as a whole and so on. These and other findings are classified by educational competencies involving understanding, reasoning, critical thinking, scientific thinking, creative thinking and problem thinking (Serebryakova, 2006).

One of the most promising forms of measurement of competences formation is, in our opinion, an exercise in interpretation. It consists of introductory material and a series of objective questions based on written material, tables, graphs, charts, maps or drawings.

For the convenience of grading Moodle contains section "Gradebook", where all the data for all measured elements of the course is presented (Figure 3). 


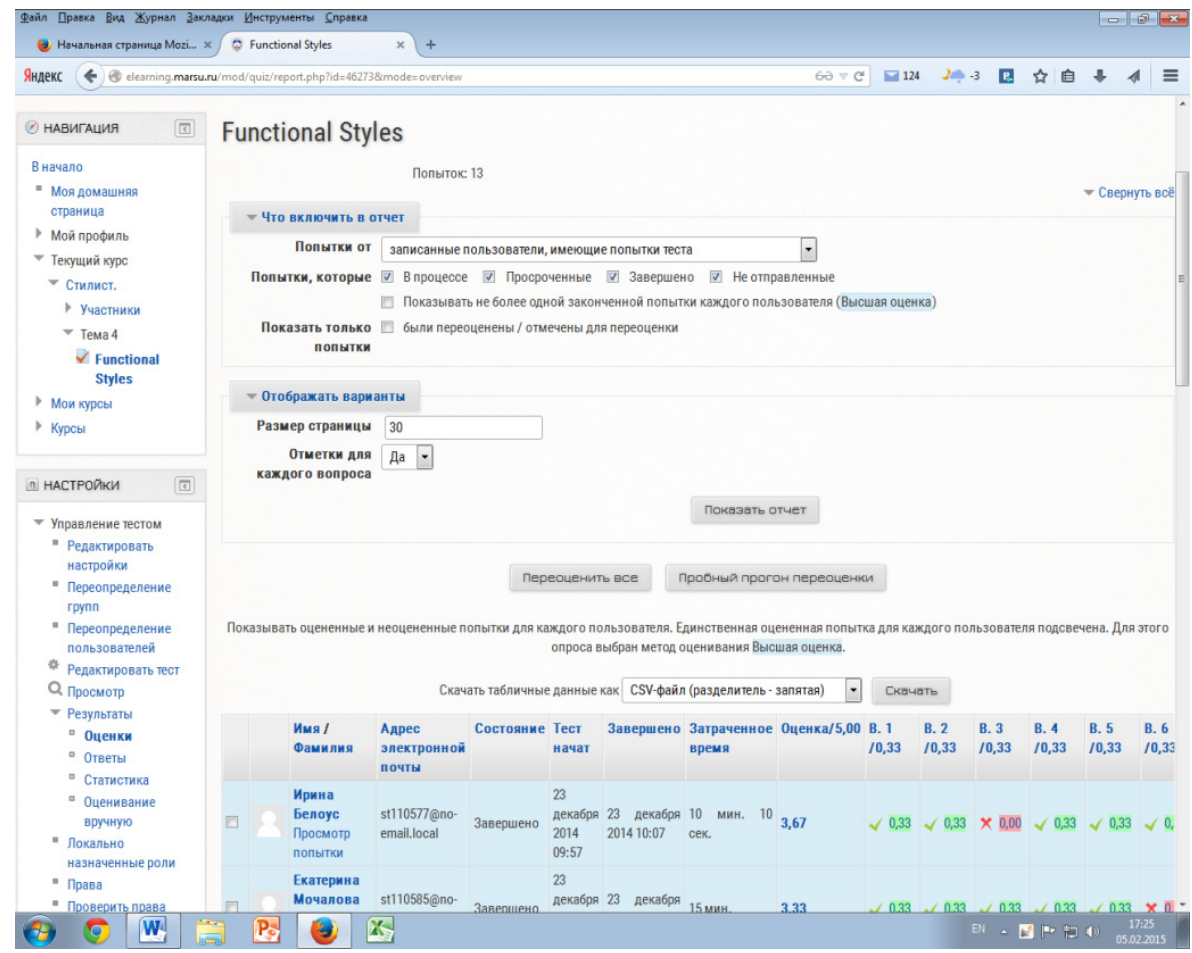

Figure 3. Gradebook 1

This "Gradebook" provides a summary field containing a total average rating on the test results and a graph showing evaluation of students in bands (Figure 4).

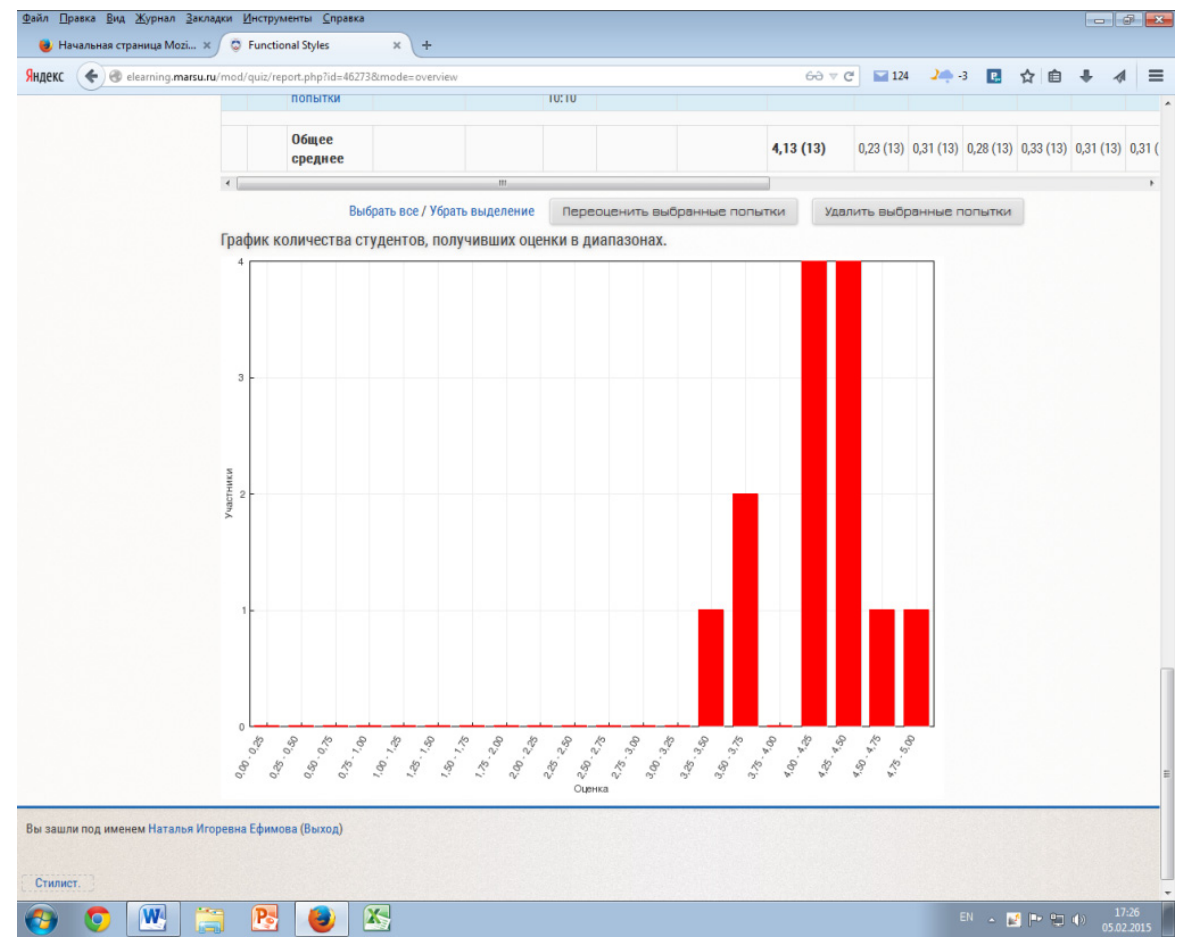

Figure 4. Schedule ranges 1 


\section{Conclusion}

The testing process involves consideration of such test quality index as reliability. Test items from different modules developed for monitoring can be used to perform final control without any need to create a new test. When using the random addition of questions in the test, each student will be provided with his own version of the final test, if they try to re-take the test, a set of questions will be changed. All questions posed are stored in a bank of questions, you can organize them by subject, which makes it possible to create tests in future on selected topics of the course, as well as throughout the course as a whole. Repeated successful fulfillment gives an indication of the stability of formed competencies of undergraduate students.

In preparing future teachers of foreign languages, it is important to control complex formation of all types of speech activity. The implementation of the educational process on the base of LMS Moodle allows to follow the dynamics of the success in training on such types of speech activity as reading and writing, besides it provides teachers with the information about shaping of lexical and grammatical skills.

It looks promising for future research to develop criteria which will allow to objectively correlate the level of certain competencies development with a range of estimates, based on the analysis of test results on the basis of LMS Moodle.

\section{References}

Glaboniat, M., \& Müller, M. (2003). Profile deutsch. Berlin, München: Langenscheidt.

Hennig, G. (1982). ALTE-Handreichungen für Testautoren. Itemtypen. New York: Newberry House.

Henning, G. (1987). A Guide to Language Testing. New York: Newbury House. http://dx.doi.org/10.1177/026553229301000308

Hutmacher, W. (1997). Key competencies for Europe. Report of the Symposium Berne, Switzerland, 27-30 March, 1996. Council for Cultural Co-operation (CDCC) a Secondary Education for Europe, Strasburg.

Isaeva, T. E. (2003). To the nature of pedagogical culture: Competence- -based approach to its structure. Teacher of the Higher School in the XXI Century (pp. 89-94). Rostov-Na-Dene, Russia.

Ivanova, O. V. (2012). Formation of the Information Competency of Foreign Language Teachers on the Bases of Person-oriented Approach (p. 204). Yoshkar-Ola.

Kolyago, A. L., \& Nikitin, P. V. (2014). Integration of disciplines of humanitarian and professional courses in training of future teachers of computer science. Fundamental Research, 5, 366-370.

Linn, R. L. (2001). Assessments and accountability (condensed version). Practical Assessment, Research \& Evaluation, 7(11). Retrieved from http://ericae.net/pare/getvn.asp? $\mathrm{v}=7 \& \mathrm{n}=11$

Serebryakova, M. A. (2006). The Systems of Educational Quality Evaluation in Russia and the USA: Comparative Analysis (Master's thesis, Mari State Teacher Training University, Yoshkar-Ola, Russia). Retrieved from http://www.dslib.net

Sysoyev, P. V., \& Evstigneev, M. N. (2014). Foreign language teachers' competence in using information and communication technologies. Procedia-Social Behavioral Sciences, 154, 82-86. http://dx.doi.org/10.1016/j.sbspro.2014.10.116

Weir, Cyril J. (2005). Limitations of the Common European Framework for Developing Comparable Examinations and Tests. Oxford: University Press. http://dx.doi.org/10.1191/0265532205lt309oa

White, R. W. (1959). Motivation reconsidered: The concept of competence. Psychological Review, 66(5), 297-333. http://dx.doi.org/10.1037/h0040934

Zaburdaeva, T. I. (2013). The algorithm of working out grammar tests on the basis of the handbook-standard "Profile Deutsch". XXI century: Results of the Past and Problems of the Present, 8, 187-193. Penza: Penza State Technological Academy.

Zaburdaeva, T. I. (2014). Perfecting tests used as the means of educational measurements on the basis of Common European Framework of Reference for Languages. In Foreign Languages: Linguistic and Methological Aspects (Vol. 26, pp. 59-65). Tver: Tver State University.

Zimnyaya, I. A. (2006). Key competences - A new paradigm of the results of modern education. Internet Journal Eidos. Retrieved from http://www.eidos.ru/journal/2006/0505.html 


\section{Appendix}

Assessment criteria

\begin{tabular}{|c|c|}
\hline $\begin{array}{l}\text { Points } \\
\text { for } \\
\text { content }\end{array}$ & $\begin{array}{l}\text { CONTENT } \\
\text { (max. } 10 \text { points) }\end{array}$ \\
\hline $\begin{array}{l}9-10 \\
\text { points }\end{array}$ & $\begin{array}{l}\text { Communicative task is successfully solved. The contents is fully disclosed. The student demonstrates } \\
\text { the ability to describe events, showing creativity and originality of thinking. The plot is clear, } \\
\text { dynamic and interesting. The text is appropriate to the given genre and style. }\end{array}$ \\
\hline $\begin{array}{l}8-7 \\
\text { points }\end{array}$ & $\begin{array}{l}\text { Communicative task is completed. The text matches the specified parameters. The student } \\
\text { demonstrates the ability to describe events. The plot is clear but trivial. The text is appropriate to } \\
\text { the given genre and style. }\end{array}$ \\
\hline $\begin{array}{l}6-5 \\
\text { points }\end{array}$ & $\begin{array}{l}\text { Communicative task is generally performed, but there are certain violations of the integrity of the } \\
\text { story. The plot is clear but has no dynamics. The text is appropriate to the given genre and style. }\end{array}$ \\
\hline $\begin{array}{l}\text { 4-3 } \\
\text { points }\end{array}$ & $\begin{array}{l}\text { Communicative task is partly performed. The content of the written text does not fully meet the } \\
\text { specified parameters. The plot is not always clear, trivial and has no dynamics. Student doesn't know } \\
\text { strategies of description. The text isn't fully appropriate to the given genre and style. }\end{array}$ \\
\hline $\begin{array}{l}2-1 \\
\text { points }\end{array}$ & $\begin{array}{l}\text { An attempt to do the item is done, but the content of the text does not meet the specified parameters. } \\
\text { The text isn't appropriate to the given genre and style. }\end{array}$ \\
\hline 0 & $\mathrm{xt}$ isn't written. \\
\hline
\end{tabular}

\begin{tabular}{cccc}
\hline & ORGANISATION AND LANGUAGE (max. 10 points) & \\
\hline ORGANISATION & VOCABULARY & GRAMMAR & SPELLING AND \\
(max. 2 points) & (max. 3 points) & (max. 3 points) & PUNCTUATION \\
& & & (max. 2 points) \\
\hline
\end{tabular}

\section{2 points}

From the point of view of organisation there are no mistakes in the assignment.

The logic of statement is observed. The student uses cohesive devices. The text is divided into paragraphs correctly.

1 point
In general, the text has a
clear structure. The text is
divided into paragraphs.
There are connecting
elements in the text.
There are some mistakes
in structure and/or in
logic and/or in coherence
of the text.

3 points

The student demonstrates the correct use of grammar structures connecting with communicative task.

There are no grammar mistakes in the assignment.

No more than 1 mistake.

\section{2 points}

The student demonstrates the correct use of spelling and punctuation.

No mistakes in spelling.

There are 1-2 punctuation mistakes that don't lead to misunderstanding.
No more than 1 mistake.

\section{2 points}

The student demonstrates the use of a good range of vocabulary appropriate to the content and function.

2-3 vocabulary mistakes.

\section{2 points}

The student demonstrates the correct use of grammatical structures.

There are 2-4 grammar mistakes that don't lead to misunderstanding.

\section{1 point}

There are 1-4 spelling and/or 3-4 punctuation mistakes in the text that don't lead to misunderstanding.

$\begin{array}{llll}0 \text { points } & 1 \text { point } & 1 \text { point } & 0 \text { points } \\ \text { The text has no clear In general, vocabulary is } & \text { There are 4-7 grammar } & \text { There are a lot of spelling } \\ \text { structure. The text isn't appropriate to the content mistakes in the text that mistakes (more than 4) }\end{array}$


divided into paragraphs. and function, but there

There are a lot of are 4-6 vocabulary

mistakes in structure

and/or in logic and/or in

coherence of the text. don't lead to and/or punctuation

misunderstanding. mistakes (more than 4)

including mistakes that

lead to misunderstanding.

\section{Copyrights}

Copyright for this article is retained by the author(s), with first publication rights granted to the journal.

This is an open-access article distributed under the terms and conditions of the Creative Commons Attribution license (http://creativecommons.org/licenses/by/3.0/). 